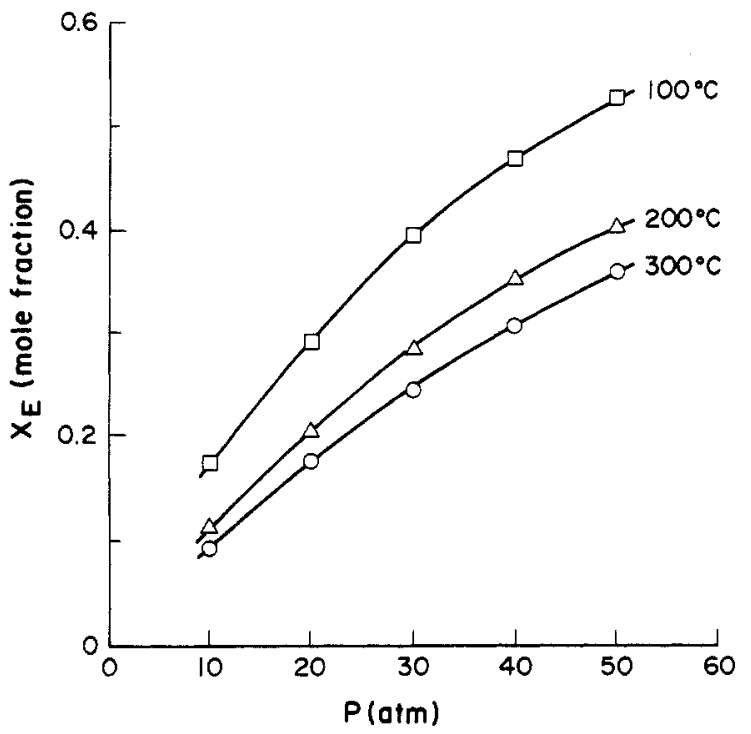

Flgure 3. Solubility of ethylene in $n$-hexatriacontane.

in $n-C_{28}$ and in $n-C_{38}$ at all three temperatures of this study and when absorbed in $n-C_{20}$ at 100 and $200{ }^{\circ} \mathrm{C}$. However, when absorption is in $n-\mathrm{C}_{20}$ at $300^{\circ} \mathrm{C}$, there is an appreciable concentration of $n-\mathrm{C}_{20}$ in the vapor amounting to 0.04 mole fraction at $10 \mathrm{~atm}, 0.02$ mole fraction at 20 and $30 \mathrm{~atm}$, and 0.01 mole fraction at 40 and $50 \mathrm{~atm}$. The calculation is based on ideal solution behavior for the paraffin in the liquid phase and the truncated two-term virial equation for the vapor. The second virial coefficient is estimated by the Pitzer correlation (6).

Figures 1-3 show the solubility isotherms of ethylene in the three paraffins studied. The solubility of ethylene in the $n$ paraffins decreases with increasing temperature. The amount of this decrease appears to decrease with increasing temperature; thus the drop in solubility from 100 to $200^{\circ} \mathrm{C}$ is $2-3$ times the decrease from 200 to $300^{\circ} \mathrm{C}$. Ethylene solubility increases with increasing pressure. The downward-bending curves of the isotherms indicate that this trend levels off slightly at higher pressures. It is also evident from the figures that at a given temperature and pressure the ethylene solubility expressed in mole fraction increases with increasing molecular weight of the solvent.

Registry No. $n-C_{20}, 112-95-8 ; n-C_{28}, 630-02-4 ; n-C_{36}, 630-06-8$; ethylene, 74-85-1.

\section{Llterature Clted}

(1) Kölbel, H.; Ralek, M. Catal. Rev. Sci. Eng. 1980, 21, 225.

(2) Albal, R. S.; Shah, Y. T.; Carr, N. L.; Bell, A. T. Chem. Eng. Sai. 1984, 39, 905.

(3) Satterfield, C. N.; Stenger, H. G., Jr. Ind. Eng. Chem. Process Des. Dev. 1985, 24, 407

(4) Stern, D.; Bell, A. T.; Heinemann, H. Chem. Eng. Sci. 1983, 38, 597.

(5) Huang, S. H.; Lin, H. M.; Chao, K. C. Fluid Phase Equilb. 1987, 36, 141

(6) Pitzer, K. S.; Curl, R. F., Jr. J. Am. Chem. Soc. 1957, 79, 2369.

Recelved for review February 17, 1988. Accepted August 1, 1988. Financial support for this study was provided by the Department of Energy through Contract No. DE-AC22-84PC70024.

\title{
Solubility of Pyrene in Binary Solvent Mixtures Containing Dibutyl Ether
}

\author{
Jordana R. Wallach, Sheryl A. Tucker, Brldget M. Oswalt, Debra J. Murral, and Willam E. Acree, Jr." \\ Department of Chemistry, Kent State University, Kent, Ohio 44242
}

Experimental solubillties are reported for pyrene in binary solvent mixtures containing dibutyl ether with $n$-hexane, cyclohexane, $n$-heptane, methylcyclohexane, $n$-octane, lsooctane, and tert-butylcyclohexane at $26^{\circ} \mathrm{C}$. Results of these measurements, combined with estimates for the excess Glbbs free energles of the blnary solvents, are used to test predictlve expressions derived from the nearly ideal binary solvent (NIBS) model. Expressions based on a volume fraction average of solute properties in the two pure solvents predict pyrene solubllties to whthin a maximum devlation of $10 \%$ and an overall average devlation of $3.2 \%$.

\section{Introduction}

This work continues a systematic study of solute solubility in binary solvent mixtures. Earlier papers have reported solubilities for lodine $(1)$, benzil $(1,2), p$-benzoquinone $(3)$, anthracene (4), benzoic acid (5), p-tolylacetic acid (6), pyrene (7), and carbazole $(8-10)$. Benzil and $p$-benzoquinone solubilities in solvent mixtures containing carbon tetrachloride were particularly interesting as the mole fraction solubility covers a 14-fold and 6-fold range, respectively. The experimental data were interpreted with solution models developed previously for solu-

\footnotetext{
- To whom correspondence should be addressed.
}

bility in systems containing specific solute-solvent interactions and with models of purely nonspecific interactions. A stoichiometric complexation model based entirely on specific interactions (nonspecific interactions ignored) required several equilibrium constants to mathematically describe the experimental results, while the nearly ideal binary solvent (NIBS) model based on nonspecific interactions described adequately the observed solubilities without introducing a single equillbrium.

The success of the NIBS approach in predicting the binary solvent effect on benzil and $p$-benzoquinone solubilities suggested the possibility that this simple solution model may provide a foundation for approximations of physical interactions even in a system known to contain chemical interactions. To date, the NIBS model has been extended to systems containing a single solute-solvent association complex $(8,11)$

$$
\mathrm{A}+\mathrm{C} \rightleftharpoons \mathrm{AC} \quad K_{\mathrm{AC}}=\phi_{\mathrm{AC}} / \phi_{\mathrm{A}_{1}} \phi_{\mathrm{C}_{1}}
$$

In $\phi_{A}^{\text {sat }}=\phi_{B}^{0} \ln \left(\phi_{A}^{\text {sat }}\right)_{B}+\phi_{C}{ }^{0} \ln \left(\phi_{A}^{\text {sat }}\right)_{C}+$

$$
\begin{gathered}
\ln \left[1+K_{A C} \bar{V}_{A} \phi_{C}{ }^{\circ} /\left(\bar{V}_{A}+\bar{V}_{C}\right)\right]-\phi_{C}{ }^{\circ} \ln [1+ \\
\left.K_{A C} \bar{V}_{A} /\left(\bar{V}_{A}+\bar{V}_{C}\right)\right]+\frac{\bar{V}_{A} \Delta \bar{C}_{B C}^{\circ}}{\left(X_{B}{ }^{\circ} \bar{V}_{B}+x_{C}{ }^{0} \bar{V}_{C}\right) R T}
\end{gathered}
$$

and to systems in which the solute (component A) complexes with both solvents (components $B$ and $C$ ) (10)

$$
\mathrm{A}+\mathrm{B} \rightleftharpoons \mathrm{AB} \quad K_{\mathrm{AB}}=\phi_{\mathrm{AB}} / \phi_{\mathrm{A}_{1}} \phi_{\mathrm{B}_{1}}
$$




$$
\mathrm{A}+\mathrm{C} \rightleftharpoons \mathrm{AC} \quad K_{\mathrm{AC}}=\phi_{\mathrm{AC}} / \phi_{\mathrm{A}_{1}} \phi_{\mathrm{C}_{1}}
$$

$$
\begin{gathered}
\ln \phi_{A}^{\text {sat }}=\phi_{B}^{0} \ln \left(\phi_{A}^{\text {sat }}\right)_{B}+\phi_{C}{ }^{0} \ln \left(\phi_{A}^{\text {sat }}\right)_{C}- \\
\phi_{B}^{0} \ln \left[1+\bar{V}_{A} K_{A B} /\left(\bar{V}_{A}+\bar{V}_{B}\right)\right]+\ln [1+ \\
\left.K_{A B} \bar{V}_{A} \phi_{B}^{0} /\left(\bar{V}_{A}+\bar{V}_{B}\right)+K_{A C} \bar{V}_{A} \phi_{C}{ }^{0} /\left(\bar{V}_{A}+\bar{V}_{C}\right)\right]- \\
\phi_{C}{ }^{\circ} \ln \left[1+K_{A C} \bar{V}_{A} /\left(\bar{V}_{A}+\bar{V}_{C}\right)\right]+\frac{\bar{V}_{A} \Delta \bar{G}_{B C}^{\text {th }}}{R T\left(X_{B}{ }^{\circ} \bar{V}_{B}+X_{C}{ }^{\circ} \bar{V}_{C}\right)}
\end{gathered}
$$

Equations 1 and 2, derived from the thermodynamic model, enable one to calculate the solute-solvent equilibrium constant from measured solubility as a function of solvent composition and the excess Gibbs free energy of the binary solvent mixture. The various terms are defined in the Glossary.

For the most part, previous studies have focused on illustrating the application of eq 1 and on comparing the calculated $K_{\text {AC }}$ values to ones based on dissimilar solution models. McCargar and Acree $(8,9,12)$ showed that eq 1 required a single equilibrium constant to describe the solubility of carbazole in ten binary dibutyl ether + alkane solvent mixtures. The carbazole-dibutyl ether equilibrium constant varied from $K_{\mathrm{AC}}$ $=22.0$ for $n$-heptane to $K_{A C}=30$ for isooctane cosolvent. Inert hydrocarbon cosolvents included both small (cyclohexane, $n$-hexane, cyclooctane) and large ( $n$-hexadecane, squalane) molecules.

Application of the extended NIBS equations to carbazole solubilities did require that the authors estimate the excess Gibbs free energles of the binary solvents via the ScatchardHillebrand solubility parameter approach. Vapor pressure data for these mixtures have not been reported in the chemical literature. Part of the observed variation in $K_{\mathrm{AC}}$ values may result from poor $\Delta \bar{G}_{a c}^{\theta x}$ estimates. To determine if this is the case, we measured pyrene solubilities in seven binary solvents containing dibutyl ether with $n$-hexane, cyclohexane, $n$-heptane, methylcyclohexane, $n$-octane, isooctane, and tert-butylcyclohexane. Results of these measurements are interpreted using the NIBS equations for nonspecific interactions, with the solvent free energies being estimated via the solubility parameter model.

\section{Experimental Section}

Pyrene (Aldrich $99 \%$ ) was recrystallized three times from absolute ethanol, giving a melting point of $151.1 \pm 0.5^{\circ} \mathrm{C}$ [literature values are $151.3(13)$ and $149-150^{\circ} \mathrm{C}(14)$ ]. Cyclohexane (Aldrich HPLC), $n$-heptane (Aldrich HPLC), $n$-hexane (Aldrich $99 \%$ ), isooctane (Aldrich HPLC), n-octane (Aldrich Gold Label), methylcyclohexane (Aldrich Gold Label), tert-butylcyclohexane (Aldrich $99 \%$ ), and di-n-butyl ether (Aldrich Gold Label, anhydrous) were stored over molecular sieves to remove trace water. Binary solvent mixtures were prepared by weight so that compositions could be calculated to 0.0001 mole fraction.

Excess solute and solvent were placed in amber glass bottles and allowed to equilibrate in a constant temperature bath at $26.0 \pm 0.1^{\circ} \mathrm{C}$ for several days. Attainment of equilibrium was verified by repettive measurements after several additional days and in some instances by approaching equilibrium from supersaturation by preequilibrating the solution at a higher temperature. Aliquots of saturated pyrene solutions were transferred through a coarse filter into a tared volumetric flask to determine the amount of sample and diluted quantitatively with methanol. Ethanol was used as the dilution solvent for all mixtures containing tert-butylcyclohexane. Concentrations were determined spectrophotometrically at $372 \mathrm{~nm}$ on either a Bausch and Lomb Spectronic 2000 or an HP 8450 A photodiode array spectrophotometer. Experimental solubilities of pyrene in the eight binary solvent systems are listed in Table I. Numerical values represent the average of between four
Table I. Comparison of Predicted and Experimental Pyrene Solubilities in Several Binary Solvent Mixtures at $26^{\circ} \mathrm{C}$

\begin{tabular}{ccccc}
\hline & \multicolumn{4}{c}{ \% dev of calcd values } \\
\cline { 3 - 4 }$X_{\mathrm{B}}{ }^{\circ}$ & $X_{\mathrm{A}}^{\text {sat }}$ & eq 3 & eq 4 & eq 5 \\
\hline \multicolumn{5}{c}{ Methylcyclohexane (B) + Dibutyl Ether (C) } \\
0.0000 & 0.0298 & & & \\
0.2625 & 0.0260 & -8.2 & -3.9 & -3.8 \\
0.4723 & 0.0223 & -10.3 & -4.2 & -4.1 \\
0.5604 & 0.0206 & -9.8 & -3.7 & -3.6 \\
0.6694 & 0.0187 & -8.7 & -3.1 & -2.9 \\
0.8301 & 0.0159 & -6.1 & -2.3 & -2.2 \\
1.0000 & 0.0130 & & & \\
\multicolumn{5}{c}{ n-Octane (B) } \\
0.0000 & 0.0298 & Dibutyl Ether (C) & \\
0.2133 & 0.0259 & -1.7 & -1.2 & -1.2 \\
0.3501 & 0.0233 & -0.8 & -0.1 & -0.1 \\
0.5155 & 0.0205 & -0.2 & +0.6 & +0.6 \\
0.6123 & 0.0190 & +0.1 & +0.9 & +0.9 \\
0.8146 & 0.0163 & +0.4 & +0.9 & +0.9 \\
1.0000 & 0.0142 & &
\end{tabular}

\begin{tabular}{ccccc}
\multicolumn{5}{c}{ Dibutyl Ether (B) $+n$-Heptane (C) } \\
0.0000 & 0.0112 & & & \\
0.1915 & 0.0143 & -5.3 & -3.0 & -3.0 \\
0.3678 & 0.0170 & -5.6 & -2.1 & -2.1 \\
0.4995 & 0.0198 & -7.7 & -4.0 & -4.0 \\
0.5744 & 0.0213 & -7.8 & -4.2 & -4.2 \\
0.7708 & 0.0254 & -6.2 & -3.8 & -3.8
\end{tabular}

$\begin{array}{lc}1.0000 & 0.0298 \\ & \text { Cyclohexane (B) + Dibutyl Ether (C) }\end{array}$

$\begin{array}{lllll}0.0000 & 0.0298 & & & \\ 0.2944 & 0.0251 & -11.4 & -2.6 & -2.2 \\ 0.5097 & 0.0211 & -15.6 & -3.7 & -3.2 \\ 0.6078 & 0.0192 & -15.7 & -3.8 & -3.2 \\ 0.7017 & 0.0172 & -14.0 & -3.0 & -2.4 \\ 0.7038 & 0.0171 & -14.0 & -3.1 & -2.5 \\ 0.8620 & 0.0137 & -7.6 & -0.8 & -0.4\end{array}$

tert-Butylcyclohexane (B) + Dibutyl Ether (C)

$\begin{array}{lllll}0.1970 & 0.0278 & -5.5 & -5.7 & -5.8\end{array}$

$\begin{array}{lllll}0.3882 & 0.0250 & -6.9 & -7.3 & -7.3\end{array}$

$\begin{array}{lllll}0.4961 & 0.0235 & -7.5 & -7.8 & -7.8\end{array}$

$\begin{array}{lllll}0.5987 & 0.0225 & -9.4 & -9.7 & -9.7\end{array}$

$\begin{array}{lllll}0.7905 & 0.0194 & -6.4 & -6.7 & -6.7\end{array}$

$1.0000 \quad 0.0159$

\begin{tabular}{ccccc}
\multicolumn{5}{c}{ Isooctane (B) + Dibutyl Ether (C) } \\
0.0000 & 0.0298 & & & \\
0.2044 & 0.0237 & -2.7 & -2.1 & -2.1 \\
0.4105 & 0.0180 & -2.7 & -1.9 & -1.9 \\
0.5112 & 0.0156 & -2.8 & -1.9 & -1.9 \\
0.6135 & 0.0134 & -2.9 & -2.0 & -2.0 \\
0.8046 & 0.0100 & -2.5 & -1.9 & -1.9 \\
1.0000 & 0.0071 & & &
\end{tabular}

$n$-Hexane (B) + Dibutyl Ether (C)

$0.0000 \quad 0.0298$

$0.2536 \quad 0.0242$

0.4650

0.5694

0.0190

$-9.6$

-9.6
-11.5

\section{$-3.6$}

$\begin{array}{ll}-11.5 & -3.1 \\ -12.1 & -3.5\end{array}$

$-11.0$

0.6635

0.0148

0.0113

$-6.4$

$-3.1$

$-3.5$

$-3.0$

$-3.4$

$-3.0$

1.0000

0.0086

${ }^{a}$ Deviation $(\%)=100 \ln \left(X_{A}^{\text {calcd }} / X_{A}^{\text {expt }}\right)$.

and eight independent determinations, with the measured values being reproducible to $\pm 1 \%$. Solubilities in the pure solvents are in excellent agreement with earlier values reported by Judy et al. (7).

\section{Results and Discussion}

The general NIBS expressions (15) for predicting solubilities in systems of nonspecific interactions depend on two different models of solution ideality: 


$$
\begin{aligned}
& R T \ln \left(a_{A}^{\text {solld }} / X_{A}^{\text {sat }}\right)= \\
& \left(1-X_{A}^{\text {sat }}\right)^{2}\left[X_{B}{ }^{0}\left(\Delta \bar{G}_{A}^{\text {ox }}\right)_{B}+X_{C}{ }^{0}\left(\Delta \bar{G}_{A}^{\text {ox }}\right)_{C}-\Delta \bar{G}_{B C}^{\text {ox }}\right] \\
& \left.\bar{V}_{A}\left(X_{B}{ }^{0} \bar{V}_{B}+X_{C}{ }^{\circ} \bar{V}_{C}\right)^{-1} \Delta \bar{G}_{B C}^{0 x}\right]
\end{aligned}
$$

and

$$
\begin{aligned}
& R T\left[\ln \left(a_{A}^{\text {solve }} / \phi_{A}^{\text {sat }}\right)-\left(1-\phi_{A}^{\text {sat }}\right)\left(1-\frac{\bar{V}_{A}}{X_{B}{ }^{\circ} \bar{V}_{B}+X_{C}{ }^{\circ} \bar{V}_{C}}\right)\right]= \\
& \left(1-\phi_{A}^{\text {sat }}\right)^{2}\left[\phi_{B}{ }^{\circ}\left(\Delta \bar{G}_{A}^{\text {m }}\right)_{B}+\phi_{C}{ }^{\circ}\left(\Delta \bar{G}_{A}^{\text {th }}\right)_{C}-\bar{V}_{A}\left(X_{B}{ }^{\circ} \bar{V}_{B}+\right.\right. \\
& \left.\left.x_{C}{ }^{0} \bar{V}_{C}\right)^{-1} \Delta \bar{G}_{\mathrm{BC}}^{\mathrm{m}}\right]
\end{aligned}
$$

Equations 3 and 4 are based on Raoult's law for the configurational contribution to the free.energy, and eq 5 is based on the Flory-Huggins model. In the above expressions $a_{A}^{\text {solid }}$ is the activity of the solid solute relative to the pure subcooled liquid, $X_{i}$ is mole fraction, and $\phi_{i}$ is the ideal volume fraction. Binary solvent properties $\Delta \bar{G}_{\mathrm{BC}}^{e x}$ and $\Delta \bar{G}_{\mathrm{BC}}^{\mathrm{m}}$ refer to the excess Gibbs free energies relative to Raoult's law and the Flory-Huggins model, respectively. Solubility data measured in each pure solvent can be used to calculate the excess partial molar Gibbs free energy of the solute $\left(\Delta \bar{G}_{A}^{e x}\right)_{\text {, and }}\left(\Delta \bar{G}_{A}^{\text {h }}\right)_{\text {r }}$. The quantities are then combined with the free energy of the binary solvent mixture to predict solubility in mixed solvents.

To date, testing of the limitations and applications of the NIBS model has been primarily restricted to binary solvent systems for which $\Delta \bar{G}_{\mathrm{BC}}^{\text {ex }}$ values could be found in the literature. There are a number of systems, such as binary dibutyl ether + alkane mixtures, that have not been studied thermodynamically. This undoubtedly will become more common as we apply the extended NIBS model to more complex systems. Excess Gibbs free energies of such systems may be estimated from the Scatchard-Hildebrand solubility parameter approach or the UNIFAC or other group contribution methods. The various group contribution methods have been reviewed in recent monographs by Acree (16) and Prausnitz et al. (17). The Scatchard-Hildebrand approach, perhaps the simplest of the predictive methods, estimates the excess Gibbs free energies from

$$
\begin{aligned}
& \Delta \bar{G}_{\mathrm{BC}}^{\mathrm{ox}}=\phi_{\mathrm{B}}{ }^{\circ} \phi_{\mathrm{C}}{ }^{\circ}\left(X_{\mathrm{B}}{ }^{\circ} \bar{V}_{\mathrm{B}}+X_{\mathrm{C}}{ }^{\circ} \bar{V}_{\mathrm{C}}\right)\left(\delta_{\mathrm{B}}-\delta_{\mathrm{C}}\right)^{2} \\
& \Delta \bar{G}_{\mathrm{BC}}^{\mathrm{h}}= \Delta \bar{G}_{\mathrm{BC}}^{\mathrm{ox}}+ \\
& R T\left[\ln \left(X_{\mathrm{B}}{ }^{\circ} \bar{V}_{\mathrm{B}}+x_{\mathrm{C}}{ }^{\circ} \bar{V}_{\mathrm{C}}\right)-X_{\mathrm{B}}{ }^{\circ} \ln \bar{V}_{\mathrm{B}}-X_{\mathrm{C}}{ }^{\circ} \ln \bar{V}_{\mathrm{C}}\right]
\end{aligned}
$$

the solubility parameters of the pure components, $\delta_{i}$.

Comparisons between experimental and predicted pyrene solubilities are tabulated in the last three columns of Table I for the seven binary solvents systems studied. Properties used in the calculations include $\bar{V}_{A}=166.5 \mathrm{~cm}^{3} / \mathrm{mol}$, based on the partial molar volume of pyrene in carbon tetrachloride (18), and the activity of the solute, $a_{A}^{\text {solid }}=0.1312$, calculated from

$$
\ln a_{A}^{\text {solld }}=\frac{-\Delta \bar{H}_{A}^{\text {fus }}\left(T_{m p}-\tau\right)}{R T T_{\mathrm{mp}}}
$$

the enthalpy of fusion data, $\Delta \bar{H}_{\mathrm{A}}^{\text {us }}=4.09 \mathrm{kcal} / \mathrm{mol}(13)$, at the normal melting point temperature $T_{\mathrm{mp}}=424.4 \mathrm{~K}$. Solvent properties used in the NIBS predictions are listed in Table II.

In general, eq 4 and 5 are comparable with overall average (rms) deviations of $3.3 \%$ and $3.2 \%$, respectively. Both equations are superior to $e q 3$, which has an overall average (rms) deviation of $7.1 \%$. In most cases, the NIBS equations slightly underpredict the experimental solubilities. More importantly, deviations for eq 4 and 5 fall almost within the experimental uncertainty of $\pm 1 \%$. This indicates that approximation of dibutyl ether + alkane $\Delta \bar{G}_{\mathrm{BC}}^{\mathrm{ex}}$ values via eq 6 introduces only a relatively small error in the NIBS predictions and makes pos-
Table II. Molar Volumes and Solubility Parameters of Pyrene, Dibutyl Ether, and Alkane Cosolvents Used in NIBS Predictions

\begin{tabular}{lcc}
\hline \multicolumn{1}{c}{ component $(i)$} & $\bar{V}_{i}, \mathrm{~cm}^{3} / \mathrm{mol}$ & $\delta_{i},\left(\mathrm{cal} / \mathrm{cm}^{3}\right)^{1 / 2 a}$ \\
\hline$n$-hexane & 131.51 & 7.27 \\
$n$-heptane & 147.48 & 7.50 \\
$n$-octane & 163.46 & 7.54 \\
cyclohexane & 108.76 & 8.19 \\
dibutyl ether & 170.41 & 7.76 \\
isooctane & 166.09 & 6.86 \\
methylcyclohexane & 128.32 & 7.83 \\
tert-butylcyclohexane & $173.93^{b}$ & $7.82^{c}$ \\
pyrene & 166.5 &
\end{tabular}

${ }^{a}$ Except for tert-butylcyclohexane, solvent properties are taken from tabulation in ref 8 . ${ }^{b}$ The molar volume is calculated from volumetric data of McLure and Swinton (19) at 30 and $40^{\circ} \mathrm{C}$. ' Solubility parameter is calculated from the enthalpy of vaporization of Majer and Svoboda (20).

sible the calculation of presumed solute-dibutyl ether association constants from future solubility measurements.

The tert-butylcyclohexane + dibutyl ether system is a notable exception. Deviations between experimental and predicted values range from $5 \%$ to $10 \%$. While one can always postulate the existence of a very weak pyrene-dibutyl ether complex to account for the relatively large negative deviations, it is more likely that the NIBS model underpredicts the solubilities because of poor $\Delta \bar{G}_{\mathrm{BC}}^{\text {th }}$ (and $\Delta \bar{G}_{\mathrm{BC}}^{\text {ox }}$ ) estimates. If this system contains only nonspecific interactions, then it is possible to back-calculate the binary solvent $\Delta \bar{G}_{\mathrm{BC}}^{\text {th }}$ values needed to "perfectly" describe the pyrene solubilities. These values can then be combined with measured carbazole solubilities in binary tert-butylcyclohexane + dibutyl ether mixtures (12) to recalculate the carbazole-dibutyl ether association constant. Doing these calculations, we find that the equilibrium constant is reduced from $K_{A C} \approx 30$ to $K_{A C} \approx 26$, but still falls within the range of $K_{\mathrm{AC}}=22$ for $n$-heptane to $K_{\mathrm{AC}}=30$ for isooctane cosolvent.

\section{Acknowledgment}

We thank Arla White for technical assistance in preparing the manuscript for publication.

\section{Glossary}

$a_{A}^{\text {solid }} \quad$ activity of the solid solute, defined as the ratio of the fugacity of the solid to the fugacity of the pure subcooled liquid

( $\Delta \bar{G}_{A}^{\text {ex }}$ ) partial molar Gibbs free energy of the solute (Raoult's law), extrapolated back to infinite dilution $\left(\Delta \bar{G}_{A}^{\text {th }}\right) \quad$ partial molar Gibbs free energy of the solute (FloryHuggins model), extrapolated back to infinite dilution

$\Delta \vec{G}_{\mathrm{BC}}^{\mathrm{x}} \quad$ excess Gibbs free energy of the binary solvent mixture based on Raoult's law

$\Delta \bar{G}_{\mathrm{BC}}^{\text {th }} \quad$ excess Gibbs free energy of the binary solvent mixture based on the Flory-Huggins model

$\Delta \bar{H}_{\mathrm{A}}^{\text {us }}$ molar enthalpy of fusion of solute

$\bar{V}_{i} \quad$ molar volume of component $i$

$X_{B}{ }^{\circ}, X_{C}{ }^{\circ}$ mole fraction composition of the solvent mixture, calculated as if the solute were not present

$X_{A}^{\text {sat }} \quad$ saturated mole fraction solubility of the solute

$\phi_{B}{ }^{\circ}, \quad$ ideal volume fraction compositions of the solvent

$\phi_{C}{ }^{\circ}$ mixture, calculated as if the solute were not present

$\phi_{A}^{\text {sat }} \quad$ ideal volume fraction solubility of solute

$\mathrm{rms} \operatorname{dev}\left(100 / N^{1 / 2}\right)\left\{\sum_{N}\left[\ln \left(X_{A}^{\text {caled }} / X_{A}^{\text {expt }}\right)\right]^{2}\right\}^{1 / 2}$

Registry No. Pyrene, 129-00-0; dibutyl ether, 142-96-1; $n$-hexane, 110-54-3; $n$-heptane, 142-82-5; n-octane, 111-65-9; isooctane, 540-84-1; cyclohexane, 110-82-7; methylcyclohexane, 108-87-2; tert-butylcyclohexane, 3178-22-1. 


\section{Literature Cited}

(1) Acree, W. E., Jr.; Bertrand, G. L. J. Solution Chem. 1983, 12, $101-13$

(2) Acree, W. E., Jr.; Rytting, J. H. J. Pharm. Scl. 1982, 71, 201-5.

(3) Acree, W. E., Jr.; Rytting, J. H. Int. J. Pharm. 1982, 10, 231-8.

(4) Acree, W. E., Jr.; Rytting, J. H. J. Pharm. Sci. 1983, 72, 292-6.

(5) Acree, W. E., Jr.; Bertrand, G. L. J. Pharm. Sci. 1981, 70, 1033-6.

(6) Judy, C. L.; Acree, W. E., Jr. Int. J. Pharm. 1985, 27, 39-44.

(7) Judy, C. L.; Pontikos, N. M.; Acree, W. E., Jr. Phys. Chem. Liq. 1987. $16,179-87$

(8) McCargar, J. W.; Acree, W. E., Jr. Phys. Chem. Liq. 1987, 17, 123-38.

(9) McCargar, J. W.; Acree, W. E., Jr. J. Pharm. Sci. 1987, 76, 572-4.

(10) Acree, W. E., Jr.; McCargar, J. W. J. Pharm. Sci. 1987, 76, 575-9.

(11) Acree, W. E., Jr.; McHan, D. R.; Rytting, J. H. J. Pharm. Sci. 1983, $72,929-34$.

(12) McCargar, J. W.; Acree, W. E., Jr. J. Solution Chem., in press.

(13) Casellato, F.; Vecchi, C.; Girelli, A.; Casu, B. Thermochim. Acta 1973, 6, 361-8.
(14) Buckingham, J. Dictionary of Organic Compounds, 5th ed.; Chapman and Hall: New York, 1982; $p 4840$.

(15) Acree, W. E., Jr.; Bertrand, G. L. J. Phys. Chem. 1977, 81, 1170-3.

(16) Acree, W. E., Jr. Thermodynamic Properties of Nonelectrolyte Solutions; Academic Press: Orlando, FL, 1984.

(17) Prausnitz, J. M.; Lichtenthaler, R. N.; Gomez de Azevedo, E. Molecular Thermodynamics of Fluid-Phase Equillbrla, 2nd ed.; Prentice-Hall: Englewood Cliffs, NJ, 1986

(18) Shahidi, F.; Farrell, P. G.; Edward, J. T.; Canonne, P. J. Org. Chem 1979, $44,950-3$.

(19) McLure, I. A.; Swinton, F. L. Trans. Faraday Soc. 1965, 61, 421-428.

(20) Majer, V.; Svoboda, V. Enthalpies of Vaporization of Organic Compounds: IUPAC Chemical Data Series No. 32; Blackwell Scientific Publications: Oxford, 1985.

Received for review February 22, 1988. Accepted August 1, 1988. ACknowledgment is made to the donors of the Petroleum Research Fund, administered by the American Chemical Society, for partial support of this research.

\title{
Thermodynamics of Binary Mixtures Containing Organic Carbonates. 2. Isothermal Vapor-Liquid Equilibria for Dimethyl Carbonate + Cyclohexane, + Benzene, or + Tetrachloromethane ${ }^{\dagger}$
}

\author{
María J. Cocero and Fidel Mato" \\ Departamento de Ingenieria Quimica, Universidad de Valladolid, 47011 Valladolid, Spain \\ Isaías García and José C. Cobos \\ Departamento de Física Aplicada II, Universidad de Valladolid, 47011 Valladolid, Spain
}

Henry V. Kehlalan

Institut de Topologie et de Dynamique des Systèmes, Université Paris VII-CNRS, 1, Rue Guy de la Brosse, 75005 Paris, France

\begin{abstract}
Vapor and liquid equillbrium phase compositions were defermined at $298.15 \mathrm{~K}$ for binary systems containing dimethyl carbonate and cyclohexane, benzene, or tetrachloromethane. The data reported satisfy the Redllch-Klster thermodynamic consistency test. The results were correlated with flve actlvity coefflcient models.
\end{abstract}

\section{Introduction}

In part 1 of this series (2) we reported excess enthalpies for dimethyl carbonate + some $n$-alkanes, + cyclohexane, + methylcyclohexane, + benzene, + toluene, and + tetrachloromethane. In this paper isothermal vapor-liquid equilibrium (VLE) data are presented for the binary systems dimethyl carbonate (1) + cyclohexane (2), + benzene (2), or + tetrachloromethane (2) at $298.15 \mathrm{~K}$. The data will serve for estimating interaction parameters for group contribution activity coefficient models. A literature search revealed indeed that no VLE data are available for dialkyl carbonates with any of the above-mentioned solvents.

\section{Experimental Section}

Materlals. All the chemicals used were from Fluka. Dimethyl carbonate (purum, $>99 \%$ ), cyclohexane (puriss p.a., $>99.5 \%$ ), benzene (puriss p.a., $>99.5 \%$ ), and tetrachloro-

\footnotetext{
${ }^{\dagger}$ This paper is a contribution to the TOM Project (1).
}

methane (puriss p.a., $>99.5 \%$ ) were used without further purification. Gas chromatographic analysis failed to show any significant impurities.

Prior to the actual measurements, the liquids were dried over a molecular sieve (Union Carbide Type 4A from Fluka). The densities and refractive indices were found to be the same as in our previous paper (2) and were in good agreement with literature values.

Apparatus and Procedure. Vapor-liquid equilibria were obtained by a saturation method. This method is based on the isothermal saturation of a flow of dry nitrogen passing through the liquid phase embedded in a packed column. The vapor phase is condensed in a liquid air trap, the condensate dissolved in a solvent adequate for gas chromatographic analysis (diethyl ether in this work). A more detailed description of the experimental equipment and operating procedure can be found in a previous paper (3).

The equilibrium temperature, $T$, was measured accurate to $0.05 \mathrm{~K}$ with a certified PROTON mercury thermometer (Model BER-MAN) previously calibrated with a Hewlett-Packard, Model $2804 \mathrm{~A}$, quartz thermometer.

The vaporized fraction of the liquid phase being very small $(<0.5 \%)$, it was not necessary to make corrections for the liquid composition calculated directly from the weighed amounts charged to the column. The mole fraction of the liquid phase is accurate to within 0.0002 . The composition of the vapor phase was determined by use of a Hewlett-Packard, Model 5890 , gas chromatograph equipped with a flame ionization detector and a Hewlett-Packard, Model 3390, electronic integrator. The column, $200 \mathrm{~cm}$ long and $1 / 4 \mathrm{in}$. in diameter, was 